Nordic Journal of Modern Language Methodology

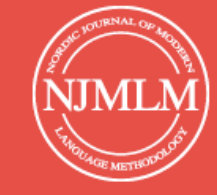

\title{
Foreign Languages and Internationalisation at a University of Education in Germany
}

\author{
Peter Dines $^{\mathrm{a}}$
}

\author{
a Ludwigsburg University of Education
}

As my title suggests, the aim of this article is to give interested readers an insight into the ways in which advanced foreign language studies are taught at Ludwigsburg University of Education (LUE), Baden-Württemberg, Germany and how this links up with the policy of internationalisation which has been developed by the university over the past 15 years or so. It is my hope that our attempts to address the challenges of teacher education and training maybe of some use to readers of this journal and possibly lead to a discussion of the issues at hand with interested parties - a discussion to which we at Ludwigsburg are more than willing to engage in, especially in view of the changes to the system of teacher education currently being prepared by the government of the state of Baden-Württemberg.

Before I go into detail on the above mentioned questions it will be helpful for an understanding of what I intend to present here to give a short overview of the general structure of higher education in Baden-Württemberg, bearing in mind that Germany has a federal political structure with the sixteen German states all organising both school and higher education in different ways.

Although there is a large degree of convergence in central organisational maters, brought about by the German Constitution, the Standing Committee of Ministers of Education (the Kultusministerkonferenz) and, as far as universities are concerned, by the Bologna process, nonetheless there are important differences between the individual states especially with respect to the structure of secondary education and the training of teachers in Baden-Württemberg. Unlike any of the other states (including surprisingly Bavaria) Baden-Württemberg has decided on a few occasions when the issue has arisen in the past not to integrate colleges of education into the comprehensive universities - this for a number of reasons which it is not possible to go into in detail here. Thus the state has the following system of institutions of higher education:

- the comprehensive universities like Heidelberg, Tübingen and Freiburg - prestigious, with a 
wide range of academic programmes and a strong focus on research

- the universities of applied science, which concentrate on narrower subject matters, especially in the area of technology, with some focus on research, especially in cooperation with private companies and state agencies

- specialised academies for music and the fine arts

- universities of education which concentrate on teacher training and education with a special concentration on pre-school, primary and lower secondary schools (called Hauptschule and Realschule) and schools for children with special needs. The teachers for the higher secondary school (Gymnasium) are educated almost exclusively at the comprehensive universities.

Currently teachers qualify with a first and second state exam in teaching, which is a combination of subject matter and the teaching licence. However, in line with the Bologna requirements the state ministries of education (we have two in Baden-Württemberg - one for schools and one for universities) are developing study and qualification programmes based upon the bachelor and master system. At the same time, the state government is overhauling the school system to make it more inclusive and comprehensive. Of course, the envisaged reforms will impact greatly on the way teachers are trained, but at the moment it is too early to say exactly what the new programmes will look like. My sense is that the universities of education will not need to change as much as the comprehensive universities, but will probably take on more responsibilities than at the present time.

The university of education at Ludwigsburg is the largest in the state with over 5,000 students, $85 \%$ of whom are female - no great surprise here - and with about 200 full-time academic and 100 administrative and other staff. About $80 \%$ of the students are preparing to become teachers, while $20 \%$ are enrolled in bachelor and master programmes, which have an educational focus but which do not lead into the teaching profession - such as culture and media education and adult education. A sizable number of students have also been accepted as doctoral and post-doctoral candidates. Students in the teaching programmes, which are planned to last for 8 semesters and include 320 ECTS points, have the following basic outline to their studies: educational science including educational psychology and counselling, one major subject, one or two minor subjects depending on whether they are training for primary or secondary education, speech training and 3 student teaching practices, one of which is a semester-long internship in school. Students are required to choose at least one of the major subjects: German, Mathematics and English as a part of their study programme. Other subjects include the sciences, technology, informational technology, the arts, the social sciences, theology and French (English and French are the only two foreign languages taught at the kind of schools LUE trains for). As English and French are taught from the first grade onwards, both subjects are offered at the primary level.

The underlying principle of teacher education at a university of education, which makes it different the training offered in many other countries and states, is the idea that the study strands (education, subject matter etc.) should operate in parallel from the first semester and ideally should be inter-connected. This means that

- students should be committed to the teaching profession from the very start

- the content of the programmes should in the broadest sense, be orientated towards the teaching profession, also from the very beginning.

This has advantages and disadvantages. One advantage is that students commit themselves from 
an early point in their studies to the teaching profession and do not "end up" in teaching when they discover that they cannot find a job anywhere else, although there is no guarantee that they will become committed and highly professional practitioners. Another is that the teaching content is geared more closely towards teaching than is often the case when students first study their subject as a B.A. or B.Sc. and then add on a post-graduate teaching qualification. The disadvantage of the system is that when students finish their studies at a university of education and do not wish to continue with the second phase - then their first state exam qualification may not be recognised in other professional areas.

Before moving on to a description and analysis of the foreign language programmes at LUE, it should be mentioned that, in theory at least, incoming students should be quite proficient already in their chosen subjects. This is supposed to be guaranteed by the Abitur (school-leaving certificate for the Gymnasium, which also functions as the entrance key to studying at a university). As far as the two languages French and German are concerned students should be linguistically at the level of at least B2 or C1 according to the Common European Framework of Reference for Languages (CEFR). They should also be familiar with important aspects of Anglophone culture, politics and society. In reality, this is unfortunately not the case or at least not the case with a majority of our beginning students, which means that as far as language teaching and cultural studies are concerned it is necessary in the first year to cover and revise a lot of ground which was supposed to have been dealt with at school. In keeping with the general principles of a UE, the various strands of the English and French study s are intended to be interconnected and to inform each other. Thus, knowledge in linguistics should be broadly related to the theory and practice of FL teaching (Fremdsprachendidaktik), while the practical language courses concentrate on those aspects of FL knowledge and competences which the prospective teacher needs in the classroom. In the following I shall give an outline of the subject areas taught by the English Department at LUE with some comments on aims, procedures and interrelationship where necessary. It should also be borne in mind that the classes and seminars described here are almost without exception taught in English. The current study programme is divided into three comprehensive modules which are graded, and are followed by a final state exam. The grades for Modules 2 and 3 count towards the final exam mark, while Module 1 ends with an intermediary pass/fail exam which determines whether the student is allowed to continue their teacher education study programme.

The content of the modules and the corresponding seminars is based upon a defined list of competences which students are expected to acquire. The competences themselves were agreed by the English departments of all six universities of education; how the competences should be realised, however, has been left to the individual universities.

Here is a selection for Modules 1 and 2:

\section{Linguistics}

Students

- are familiar with basic linguistic research methods and procedures and can apply them critically - can reflect on the socio-cultural and linguistic frame of reference of language use and critically observe their own use of language

- take account of the specific multi-lingual aspects when applying linguistic, literary and cultural theories and methods

- are familiar with the causes and effects of the expansion of the English language.

The theory and practice of FL teaching and learning (Fachdidaktik) 
Students

- are familiar with theoretical issues in FL teaching and second language acquisition, can derive basic didactic principles from these insights and apply them to intercultural, communicative FL methodology

- are familiar with the CEFR and understand its significance for setting educational standards and developing syllabi.

\section{Literature and cultural studies}

Students

- master the basic literary research methods and procedures and can apply them critically

- are familiar with selected research and procedural methods in the area of cultural studies and relate them to heterogeneity, inclusion and inter-culturality

- take account of the specific aspects of multi-lingualism and inter-culturality when applying and reflecting on linguistic, literary and cultural theories and methods

- can read and understand literary works and their realisation in various media within the framework of their own culture and the cultures whose language they are acquiring.

\section{Language practice}

Students

- have mastery of knowledge and skills as defined by the C1 level of CEFR.

All of this is, of course, quite abstract, theoretical and indeed intimidating and needs to be translated into practical applications, which is done in the form of seminars and practice classes, for which there are course descriptions, as presented in the following:

\section{Module 1 - Introductory Studies (to be studied in semesters one and two)}

1.1 Introduction to linguistics

Basic linguistic concepts such as phonetics and phonology, morphology, semantics, syntax, pragmatics and geographical and social variation. The emphasis is on the kind of linguistic knowledge that a teacher should be familiar with in order to be able to analyse his/her own linguistic situation and cope with the challenges of FL teaching and learning.

1.2. Introduction to the teaching of English

An overall view of the theoretical foundations of language learning and teaching, pedagogical applications and implications, beliefs about teaching and learning, learning strategies, the history of language teaching, teaching receptive and productive skills, teaching and learning a foreign language in primary or secondary school, teaching vocabulary and grammar, practical considerations in the classroom (planning lessons, assessment, classroom management).

1.3. Applied linguistics

Pragmatics, discourse analysis, conversation analysis and their relevance for language teaching interaction, second language acquisition, language variation. Notice the almost inevitable and intentional cross-over with the introduction to linguistics course.

1.4. Language skills I

A survey (revision, clarification, development) of important English language issues (e.g. the meaning and use of tenses, gerunds and infinitives) as well as competence training in listening, speaking, reading and writing at an advanced level.

Module is completed with a 2 hour final written exam covering 1.1, 1.2 and 1.4. For 1.3 students must document active and regular participation.

\section{Module 2 - Intermediate Studies (to be studied in semesters three to five)}




\subsection{Introduction to literature}

A survey of the history and genres of English and American Literature and the New Literatures in English, a survey of theoretical approaches to reading and interpreting literature, such as New Criticism, Psychoanalytical Criticism, Feminism, New Historicism and Post-Structuralism.

2.2. Introduction to the culture and civilisation of the English-speaking world

Various aspects of history, politics, sociology and popular culture with a focus on Great Britain and the United States of America, the importance of English as a mother tongue in many other countries and as a global lingua franca.

2.3. Primary-specific ways of teaching

The theoretical foundations of early foreign language learning, the key principles of teaching English to young learners aged 6 to 10 with focus on learning words and grammar, story-telling, acquiring literacy, the use of hand-puppets and other teaching materials, testing and assessment and the transition from the primary to the secondary level

or

Secondary-specific ways of teaching

Planning a lesson, teaching aims/goals, presenting and practising vocabulary and grammatical structures, using a reading text, reading/writing/listening activities, asking questions, giving instructions and communicative activities.

2.4. Teaching practice seminar

Students use this seminar to address issues arising from their semester teaching practice.

2.5. Language skills II: Advanced oral skills

Developing skills in spoken English including pronunciation practice, learning active and passive phonemic transcription, recognition and application of syllable and word stress, phonetic and phonological theory.

2.6. An intermediate seminar in FL theory and practice, linguistics, cultural studies or literature

2.7. Practice Advisory

Preparation for the semester teaching practice.

2.8. Language skills III: Developing advanced writing skills

From sentence structure to paragraphs and essay writing. The course covers several types of essay structure as well as practising paraphrasing and quoting. Typical non-native speaker mistakes and English collocations are analysed.

The Module 2 grade is based upon an aggregate of the marks for 2.1, 2.2, 2.3 and 2.8. For 2.4-2.7 students must document active and regular participation. Grades are given on the basis of classwork, essays and/or final exam. Semester 5 is usually taken up by the semester TP, in which students teach their major and one minor subject. The TP is assessed on a pass/fail basis and involves an intensive counselling by both university lecturers and mentors at the school.

\section{Module 3 - Advanced Studies (to be studied semesters six to eight)}

As students move in to advanced studies the programmes become less defined and are based to quite a large extent on the professors' and lecturers' personal teaching and research interests.

Students are therefore able to choose from quite a large range of offers in accordance with their own special interests. Thus for seminars 3.1 to 3.3 a selection of typical advanced seminars is given here.

3.1. One advanced seminar in applied linguistics, for example

Advanced pragmatics

Bilingual education: Immersion and CLIL 
Discourse analysis in English

3.2. One advanced seminar in literature and/or cultural studies, for example

Charles Dickens and the Victorian age

Romanticism

Shakespeare and his contemporaries

Selected English Poetry

Utopian and dystopian fiction

From Empire to Commonwealth

Race, Gender, and the Identification of the American Dream: A Short Survey of Modern

American Drama

Sports in the USA

Current issues in American education

The White House and the world

3.3. Once advanced seminar in the theory and practice of FL teaching and learning, for example

(Fachdidaktik)

Teaching reading and literature

Creating a differentiated classroom

Language in classroom interaction

Making English come alive through drama

Intercultural aspects of FL teaching

3.4 Language skills IV: Developing media and discourse literacy

Feature films from the English-speaking world are viewed and discussed, with emphasis not only on personal viewing reactions, but also on film-analytical dimensions, production techniques and historical styles of portrayal. Films are selected mainly according to the cultural significance of their themes (historical portraits, political and social topics, literary films, etc.).

3.5 Interdisciplinary seminar

Teaching music and CLIL in the classroom

3.6 / 3.7 Project advisory seminar and independent study)

Students receive help in choosing, developing and working on an independent study, which is related to their own research interests in cooperation with a professor / lecturer.

The Module 3 grade is based upon an aggregate of the marks for 3.1 to 3.4 and 3.6 3.7. For 3.5 students must document active and regular participation. Grades are given on the basis of classwork, essays and/or final exam.

The First State Exam in English takes the form of an oral exam, which is based upon topics in FL teaching, linguistics and literary and cultural studies, which candidates select together with their examiners some months in advance. Students may also choose to write their final dissertation on a topic related to English studies and FL teaching.

One important expectation (unfortunately not a requirement) of the study programme is that students spend at least four months in an English-speaking country within the framework of study abroad, which leads me into the second major topic of this article. I shall begin by describing briefly the process of internationalisation in which LUE is engaged. The idea of internationalisation as a formal policy came relatively late to the universities of education in Baden-Württemberg. Although they had had individual partnerships going back in some cases to the 1970s it was only in the mid-1990s that they received approval and the finances to establish 
offices of international programmes (akademische Auslandsämter) from the state Ministry of Science. This development resulted from certain basic requirements posed by the European Commission in connection with the introduction and implementation of the SOCRATES programme and the concomitant reform of the ERASMUS programme, which needed to be centrally administered in the participating universities. A further step in the recognition that universities of education needed an internationalisation came with the so-called "Pisa shock" of 2001/2 when Germany was confronted with the possibility that its school education system was not all that it was cracked up to be and German schools on average achieved only mediocre results. In spite of the controversial interpretation of the Pisa findings it was eventually accepted that German institutions of higher education responsible for teacher training had something to learn from other countries but found this difficult if they were not internationally networked. The flurry of visits by high-ranking officials to countries like Finland and Japan seemed rather like a rather costly over-reaction but did have the effect of putting internationalisation on the official agenda. In the meantime international relations have become an integral part of both the mission papers and the development plans of all six UEs and they are all well on the way to becoming internationally orientated institutions.

At LUE the situation is as follows: it has an akademisches Auslandsamt with almost three fulltime positions reporting to the rectorate via the provost for academic and international affairs. LUE participates in and coordinates a number of international programmes: ERASMUS, COMENIUS (3 major projects as coordinator), two DAAD (German Academic Exchange Service) programmes supporting the German language and culture in South-East Europe, two international projects funded by the Baden-Württemberg Foundation on migration and interreligious dialogue, two state-to-state student exchange programmes with the USA, a DAAD development programme on educational leadership with Egypt, scholarship exchange programmes funded by the DAAD and the Baden-Württemberg Foundation, and a number of smaller projects funded by such organisations as the Danube-Swabian Cultural Foundation of Baden-Württemberg to support activities in SE Europe. In terms of numbers: LUE sends out and receives about 200 students per year on study or practice abroad programmes, while also sending out and receiving about 40 faculty and staff members to partners each year. LUE has over 70 international partners in more than 30 countries - some of the partnerships are especially intensive - with some universities in the US, Russia, Israel, Japan, China, the UK and France including student, faculty and academic exchange.

One of the challenges of study and practice abroad is to find partners in English-speaking countries especially for the students of English who need to fulfil the study abroad expectation. LUE has been quite successful in this respect. Exchange programmes with English-speaking countries can only really succeed on the basis of balance of numbers and reciprocal arrangements, so in order to send Ludwigsburg students to British or US partners it is necessary to succeed in encouraging British, American, Australian students to come to Ludwigsburg. The difficulties here arise for a number of reasons: linguistic, cultural and financial. It is a well-known fact that with the spread of English as a lingua franca the willingness of anglophone students to learn a foreign language has been in steady if not sharp decline over the last twenty years or so. Although a stabilisation point has apparently been reached (at quite a low level), most students in anglophone countries do not have proficiency in a foreign language and if they do it is unlikely to be German, which means that in order to study at a German university there must be an offer of at least some courses taught in English. Together with a lack of FL proficiency there also comes a certain isolationist attitude amongst many students - not knowing a FL can inhibit the development of a curiosity of other cultures (this is not to be confused with xenophobia). 
Financially students from anglophone countries are under greater stress than, say, German students because of the relatively high costs of tuition (German students hardly pay any tuition at all), which means that students from Britain or the US, for example, need to know that they will not lose expensive study time by studying abroad. LUE has introduced a number of measures to help solve these problems - some academic, some financial and some administrative.

\section{Academic measures}

LUE offers a number of courses taught in English as well as practical courses in which a lack of knowledge in German is not necessarily a hindrance. Thus, all of the courses in the English department are taught in English, which means that students of cultural studies or TESOL will a find a number of seminars which can count towards their home degree. In addition, because LUE offers both a full qualification and an additional certificate in bilingual FL the bilingual subjects (politics, history, geography and occasionally one or two others) regularly offer content seminars taught in English, which can count towards general education or international studies. Students of sport, fine art and music have the chance to take practical courses in dance, gymnastics, athletics etc., painting, drawing sculpture, or choir, orchestra, singing and so on. For a few years now LUE has invited faculty members from partner universities (mostly outside the EU) to teach seminars in English either on a semester basis or as short courses (ca. 4 weeks). This programme which we have called "Bringing the world to Ludwigsburg" has been particularly successful in attracting American professors, who receive payment for the course and accommodation provided by LUE. Frequently their own university provides additional funding for travel. In 2013 seven faculty members availed themselves of this opportunity. Another way in which balance can be maintained is by offering visiting faculty the opportunity to offer short courses from 1 to 2 months for their own students in Ludwigsburg. In 2013 there have been four groups of German learners with their professors, one group of art students and one of education students. LUE helps organise accommodation and provides teaching and learning facilities as well as support tutors and additional specialist lectures given by Ludwigsburg faculty. The numbers count towards balance.

Student exchange is very often supported or even driven by faculty interest so that involving lecturers in teaching experiences at home and abroad has proved an excellent investment. Thus with some partners LUE regularly holds joint symposia alternately at Ludwigsburg and the partner university on cooperative teaching and research projects. The faculty involved become ambassadors for the partnership. The "Bringing the world to Ludwigsburg" programme additionally has the advantage of offering courses taught in English in Ludwigsburg by native speakers for those students who do not otherwise have the opportunity to participate in study abroad themselves.

\section{Finance}

Clearly internationalisation comes at a price. The International Office itself is funded largely by the university (running and personnel costs). Faculty exchange costs arising in Ludwigsburg are covered by internally and to some extent externally by the Ministry of Science and by the various projects which were mentioned above. Scholarships are provided for outgoing and incoming students by the ERASMUS programme, the DAAD, the Baden-Württemberg Foundation and the Ministry of Science. Students and faculty can also of course apply to private and public organisations such as the Fulbright Foundation.

\section{Administration}


In order for study abroad to succeed it is necessary to provide good, reliable support measures for incoming and outgoing students. This involves help with applications, funding opportunities, organising learning agreements and social support. For this purpose LUE has two established two positions in the International Office.

\section{Study and practice abroad}

Over the years LUE has built up a network of excellent bilateral partnerships for study abroad and exchange particularly with the US: North Carolina, New York, Virginia, Kentucky, Tennessee, Ohio, Oregon, California, Montana and Wyoming. Especially the smaller provincial institutions find a good fit with LUE. In addition our students also have the opportunity to work as classroom language assistants in US schools; thus one immersion school in Charlotte, NC, employs two cohorts of six Ludwigsburg students each year for six months to act as native speakers in the classroom.

Finally it needs to be said that as an alternative to English language students benefiting from study abroad in English-speaking countries we have had great success with our exchanges with the Scandinavian countries and Finland, so that in the meantime a semester spent at one of partners is accepted as fulfilling the study abroad expectation. This is because not only do our Scandinavian and Finnish partners offer high quality courses taught in English, but also because of the very high level of English spoken by the population at large.

LUE is engaged in a process of deepening and expanding its international relations; one area in which it needs to develop more is encouraging more students from partner universities to study education with us. Until now the state exam system has been somewhat of an obstacle in this respect, but it is hoped that with the bachelor and master system soon to be introduced into the teacher training programmes in Baden-Württemberg this situation will improve, especially if we can find ways, like our Scandinavian partners, to offer more courses taught in English with an international content base. 